\title{
Bringing Breakthroughs in Science to the Public Through Webcasting
}

\author{
Carol A. Christian \\ Space Telescope Science Institute, 3700 San Martin Drive, Baltimore, \\ $M D 21218$ USA
}

\begin{abstract}
In the rapidly changing milieu of space science, keeping the public informed and engaged in the progress of science is challenging. Beautiful images, scientific artifacts, and exciting space launches can be a compelling hook but the challenge for scientists and educators is to provide context and basic information that is equally exciting. For the past 5 years, the use of Internet video streaming (webcast) technology has grown in popularity. We have used this technology to bring together scientists, educators and the public to provide virtual access to the research environment for the audience. The growth of new technologies will provide new opportunities for the public to "get behind the scenes" of observatories and laboratories to better appreciate the texture of scientific research as well as the scientists and technical personnel engaged in investigative endeavors.
\end{abstract}

\section{Introduction}

Webcasting is a technology that emerged several years ago to bring audio/video information to users across the Internet. Through this technology, users have access to a plethora of information: rebroadcasts of radio programs (especially sports), video playback of major news events, and other uses of widely varying origin and quality.

A number of us began using webcasting in the early 1990's to study the effectiveness of the technology in an educational setting. We found that webcasting is useful to inform and engage the public in rare or special events (such as the launch of the Space Shuttle, or a solar eclipse) that they did not have an opportunity to experience in person. We found that we could bring students, teachers and other audiences into the research environment such as Space Telescope Science Institute, CERN or the McMurdo Research station through a virtual presence via webcasting. We were able to create a live public dialog between the public and scientists in a variety of environments, including within the science museum setting. As an ancillary benefit, we found that webcasting can be used as a communication tool within a discipline or a specific, focused research project.

Experience has shown that a webcast itself, in isolation, is most useful to individuals with good advanced knowledge of the subject matter. For example, webcasting of a conference or scientific colloquia have "stand alone" value. We found that webcasts to audiences less familiar with a subject (such as the flight 
operations of the Hubble Space Telescope) were more effective when integrated with high quality, informative material on a related website.

This paper presents a few examples of the range of webcast types with samples of the materials that supplement and enhance webcast use.

\section{Events}

\subsection{News and Press Conferences}

Events such as press releases and other special events can inform the public about recent scientific results. In the past, press conferences were attended only by the media and journalists and press release materials were provided to the media in hardcopy form. As a result, the information passed on to the public appears as heavily edited, and often sensationalized versions of the actual presentations. Through webcasting, we have been able to allow the interested public to obtain information about scientific results first-hand.

Certainly, news items that appear in the press or in the broadcast media serve to draw attention to new scientific results. By supporting the media and also publishing all the material provided to the press online, the public can access the originating material including: the context of the news release with specific articulation of the scientific results, implications of the new results, background information and all images and multimedia including the webcast file. Therefore users have the ability to watch the press release itself, either live or from the archive and link to all the other available materials. The webcast link is integrated in with all other links so that the user clearly sees all the resources created. We find the webcasts particularly useful because they include interactions among the scientists as well as question and answer sessions between the scientists and the press (cf., http://hubblesite.org/news_.and._views/).

\subsection{Rare Events}

We have been able to bring other events such as solar eclipses, launches of rockets and the Space Shuttle, and other activities to the public with webcasts (cf., http://www.exploratorium.edu/eclipse/2002/). Such events draw a wide audience during the event, and also enjoy a considerably healthy shelf-life, especially when augmented with additional web resources. One of the keys to successful webcasting of live events is the presence of a broker or intermediary who can explain events, interview scientists and other individuals at the event site and thereby create a solid connection between the activity and the internet audience.

\section{Radio/Internet Simulcasts}

We created the unique series of radio/Internet simulcasts for the Tour the Cosmos programs (Christian 2001). The internet webcasts consisted of a RealPlayer(C) audio/video stream broadcast simultaneously with an on-air radio program. We chose astronomical scientific results as the content for the series. The webcast stream comprised the audio from the radio program and images or graphics relating to the topics being discussed. For several programs, we post-produced the audio/video stream in a slide show format to perfect the 
synchrony between the discussion between the radio show participants and the visual images.

We converged on an excellent model for the radio program itself. The featured guests were scientists with recent new results from the Hubble Space Telescope. Also participating were a "generalist" outreach scientist with experience in science communications with the public. The role of the generalist was to provide to overall scientific context for the discussion. Another participant was the informal science educator and for Tour the Cosmos, this individual was a planetarium director who was adept at answering all the very general astronomy questions posed by call-in and write-in listeners. The radio program was hosted by a radio personality skilled at interviews who served as the audience surrogate.

Through the combination of the radio participants and the visual materials, webcast viewers accessed a suite of resources on the chosen subjects and could also link to other educational materials available through the main Tour the Cosmos website. Again, our experience emphasizes that the webcast of the live event and the availability of archived materials is greatly enhanced when the audio/video streaming files are interwoven with other internet educational and informative resources.

\section{4. "Live From" Series}

A number of us at Space Telescope Science Institute (STScI) and the San Francisco Exploratorium science center have collaborated for several years on webcasts aimed at bringing the public into the research life of scientists. Physical visits of large numbers of the public into our research facilities are clearly impractical yet we know that the attentive public is interested in how scientists conduct their investigations. We created two projects and the first in the mid 1990's called Looking Beyond Boundaries linked scientists and engineers at STScI with a public audience at the Exploratorium. The series of programs was held each day for a week during the second Servicing Mission for the Hubble Space Telescope.

A more recent series entitled Origins and Observatories expanded the interactions to the flight operations areas at STScI and at Goddard Space Flight Center, to the clean room where Hubble instruments are assembled and astronaut training takes place and to the offices of scientists and technical staff processing data for research and for release to the public.

The critical components of the webcast were the presence of a broker or explainer who could guide the live audience discussions as they interacted with the remotely located personnel on the U.S. East Coast. The "Live From" type events are embedded in rich websites with other multimedia and numerous links to additional materials and other websites (c.f., http://www.exploratorium.edu/origins/hubble/live/webcasts.html).

\section{Scientific and Technical Conferences and Lecture Series}

Emboldened by our success with using webcasting in a public venue, we began to use webcasting for scientific and technical conferences, lecture series and vari- 
ous internal activities at STScI. For the conferences, we linked to the conference website hosted by the organizing committee and produced a live webcast during the conference proceedings. At the end of the conference, we archived the webcasts, individually linking each speaker's presentation to their title keyed to a conference schedule. We also linked viewgraph packets (as power point or some other format) for presentations provided to us by the speakers.

We found that interested scientists or engineers needed little ancillary information other than the conference website itself. This also was true for our weekly lecture series, so the website hosting the live webcast and subsequent archive is simple to construct. We were pleased to discover that quite a few universities took our suggestion to set up a computer with an LCD projector in a classroom or meeting room and let the conference run all day. In this way, students, faculty and interested staff could stop by to hear a particular lecture as their schedule's permitted.

Subsequently we have found that the conference archives have a good shelf life. In particular, in the spring of 2002, STScI hosted a symposium, Astrophysics of Life and many scientists remarked that the archive served as a good preparation for this BioAstronomy 2002 conference.

In multi-disciplinary endeavors such as Astrobiology that depend on fruitful interactions among researchers in different disciplines, we anticipate that webcasting coupled with some well designed supplementary material made available on the internet will provide invaluable communications tools for scientists.

Acknowledgments. This work is supported by a contract, NAS5-26555, to the Association of Universities for Research in Astronomy, Inc. for the operation of the Hubble Space Telescope at Space Telescope Science Institute. The input and experience of numerous individuals including Hugh Wilson, Calvin Tullos, Gary Gladney, Ed Weibe, Bryan Preston, Greg Bacon and John Stoke is acknowledged.

\section{References}

Christian, C.A., Eisenhamer, B., Steiner, M., \& Kakadelis, S. 2001, Webnet, 3, 30 . 